\title{
A STUDY ON THE CLINICAL PROFILES OF PATIENTS WITH LEPRA REACTIONS TYPE 1 AND TYPE 2 REACTIONS COMING TO THE OPD AT TERTIARY CARE CENTRE IN WESTERN UTTAR PRADESH
}

\author{
Pallavi Kashyap ${ }^{1}$, D. Ramachandra Reddy² \\ ${ }_{1}^{1}$ Final Year Postgraduate Student, Department of DVL, TMMC \& RC. \\ ${ }^{2} H O D$, Department of DVL, TMMC \& RC.
}

\section{ABSTRACT}

\section{BACKGROUND}

Type 1 reaction is a Type IV Hypersensitivity reaction in Borderline leprosy occurring in early treatment, also called reversal reaction affecting those with Borderline leprosy upgrading to tuberculoid type or any patient with unstable cell mediated immunity. Type 2 reaction is a Type III hypersensitivity reaction occurring in Borderline Leprosy (BL) downgrading to Lepromatous Leprosy (LL) late during treatment and is a humoral antibody antigen reaction to immune complexes. Uttar Pradesh still harbors $23 \%$ of total leprosy cases reported in India, according to the latest census [1].

Study Design- A longitudinal study carried from the year 2015 to 2018

Setting- Study was conducted at a Tertiary Care Centre in Western Uttar Pradesh.

Inclusion Criteria- Patients who voluntarily participated in the study and aged 10 and above were included in the study.

Exclusion Criteria- Patients who refused to participate in the study.

Objectives-

1. To observe the clinical features of the patients with Hansen's disease Type 1 and Type 2 reaction along with histopathology

2. G6PD analysis for all the patient and rendering treatment accordingly

3. To analyze effectiveness of Center of Disease Control and Prevention recommended therapy over Indian MDT therapy.

\section{MATERIALS AND METHODS}

Patients were included according to the inclusion criteria and all the clinical features were observed and recorded in a pro forma. Basic investigations along with G6PD analysis was done with all 50 patients. CDC therapy was given to all the patients in contrary to the MDT therapy and downgrading of pole with recurrence of reaction was recorded. Patients were followed up accordingly.

\section{RESULTS}

Out of 50 patients $70 \%$ of the patients were found to be having Type 2 reaction while $30 \%$ patients had Type 1 reaction. $18 \%$ patients presented with G6PD deficiency. 10\% patients were found to be having resistant tuberculosis along with Hansen's disease. Only 18\% relapse cases observed along with G6PD deficiency.

\section{CONCLUSION}

We concluded that G6PD analysis before starting on Dapsone therapy is mandatory and prevent hemolysis. CDC therapy proves to be the best rather than MDT therapy to prevent recurrences and prevent resistance to Rifampicin in tuberculosis patient as well.

\section{KEYWORDS}

CDC Therapy, G6PD Analysis, Hansen's Type 1 and Type 2 Reaction.

HOW TO CITE THIS ARTICLE: Kashyap P, Reddy DR. A study on the clinical profiles of patients with lepra reactions type 1 and type 2 reactions coming to the OPD at tertiary care centre in western uttar pradesh. J. Evolution Med. Dent. Sci. 2018;7(08):993997, DOI: $10.14260 /$ jemds/2018/227

\section{BACKGROUND}

Hansen's disease found by G. H. Hansen in Norway in 1973, causative organism is Mycobacterium leprae, an obligate, acid fast, gram positive bacilli. It causes demyelination[2] of the peripheral nerves by infiltrating Schwann cells of axon. Spread occurs through respiratory droplets,[3] sebum on direct contact with the patient.[4] Parkinson's gene, a region on chromosome 10p13, TLR2, LTA, PACRG, PARK2 susceptibility [5] to this gene due to defect in cell mediated immunity, does not make leprosy a hereditary disease. Cardinal signs of leprosy: Hypo pigmented hypo aesthetic

'Financial or Other Competing Interest': None.

Submission 12-01-2018, Peer Review 07-02-2018,

Acceptance 12-02-2018, Published 19-02-2018.

Corresponding Author:

Dr. D. Ramachandra Reddy,

Professor and HOD, Department of DVL,

Flat No. 104, E-Block, Staff Quarters, TMU University,

Badarpur Road, NH-24, Moradabad, Uttar Pradesh.

E-mail: d.ramachandrareddy52@gmail.com

DOI: $10.14260 /$ jemds/2018/227

\section{(c) (i) $\odot$}

patches, thickened and tender peripheral nerves, Acid fast bacilli demonstration in the skin and nasal smears with Zeihl-Neelsen stain.

Reactions are divided as

\begin{tabular}{|c|c|}
\hline $\begin{array}{c}\text { Type I Lepra reaction } \\
\text { (Reversal reaction) }\end{array}$ & $\begin{array}{l}\text { Type II Lepra reaction } \\
\text { (ENL \&ENN) }\end{array}$ \\
\hline $\begin{array}{c}\text { Type IV Hypersensitivity reaction } \\
\text { in borderline leprosy }\end{array}$ & $\begin{array}{c}\text { Type III hypersensitivity } \\
\text { reaction in lepromatous } \\
\text { leprosy }\end{array}$ \\
\hline Early in the course of treatment & $\begin{array}{c}\text { Late in the course of } \\
\text { treatment }\end{array}$ \\
\hline $\begin{array}{l}\text { Borderline shifting towards } \\
\text { tuberculoid leprosy in upgrading } \\
\text { reaction after therapy } \\
\text { Borderline shifting to } \\
\text { lepromatous leprosy in } \\
\text { downgrading reaction sequelae } \\
\text { of the disease } \\
\end{array}$ & $\begin{array}{l}\text { Lepromatous Leprosy (LL) } \\
\text { and Borderline Leprosy } \\
\text { (BL) after therapy will go } \\
\text { for upgrading }\end{array}$ \\
\hline $\begin{array}{l}\text { Unstable cell mediated } \\
\text { Immunity }\end{array}$ & $\begin{array}{c}\text { Humoral Ag-Ab reaction to } \\
\text { immune complexes }\end{array}$ \\
\hline Both multi and pauci bacilla & Multi bacillary \\
\hline
\end{tabular}




\section{MATERIALS AND METHODS}

A complete history taking was done and clinical features were recorded in patient pro forma. Patients were thoroughly investigated with Glucose 6 Phosphate Dehydrogenase enzyme, Complete blood count, Liver Function Test, Kidney Function Test, Blood Grouping and RH typing, Urine R+M, General blood picture After ruling out G6PD we started Dapsone as a routine for all the patients and G6PD deficient cases were started with Moxifloxacin $400 \mathrm{mg}$ for recommended period and observing the response of any recurrence. Every day dose of Rifampicin $450 \mathrm{mg}$ and Dapsone $100 \mathrm{mg}$ and Clofazimine $100 \mathrm{mg}$ for recommended period of time was given. Thalidomide was started and explained the hazardous teratogenic side effects of Thalidomide [6] to the patient and drug was started after taking patients consent. Patients were advised to come for follow up after every 15 days initially and later after every 1 month. Corticosteroids were started for all the patients with the recommended dosage of $1 \mathrm{mg} / \mathrm{kg}$ body weight, initially specially in the cases of Type 2 reaction. $20 \mathrm{mg}$ of Prednisolone twice daily was started for a period of 2 weeks and gradually tapered according to the improvements observed in the patient [7]. Before starting on with corticosteroids the diabetic history of the patients was taken into consideration.

\section{RESULTS}

Out of 50 patients who fulfilled the inclusion criteria $70 \%$ of the patients were found to be having type 2 reaction while $30 \%$ patients had type 1 reaction.

Before starting on with the CDC therapy $58 \%$ patients gave the history of multiple recurrences and $48 \%$ with single episode of reaction, downgrading of reaction was seen amongst the patients and hence CDC treatment was started for all the patients. After follow-up of 2 years minimum gradual decrease in the downgrading of leprosy and recurrences of reaction was recorded only in $18 \%$ patients presented with relapse.

Further it was observed that only patients who were having G6PD value less than $6.5 \mathrm{u} / \mathrm{g} \mathrm{Hb}$ and were not started on with the Dapsone therapy showed relapse.

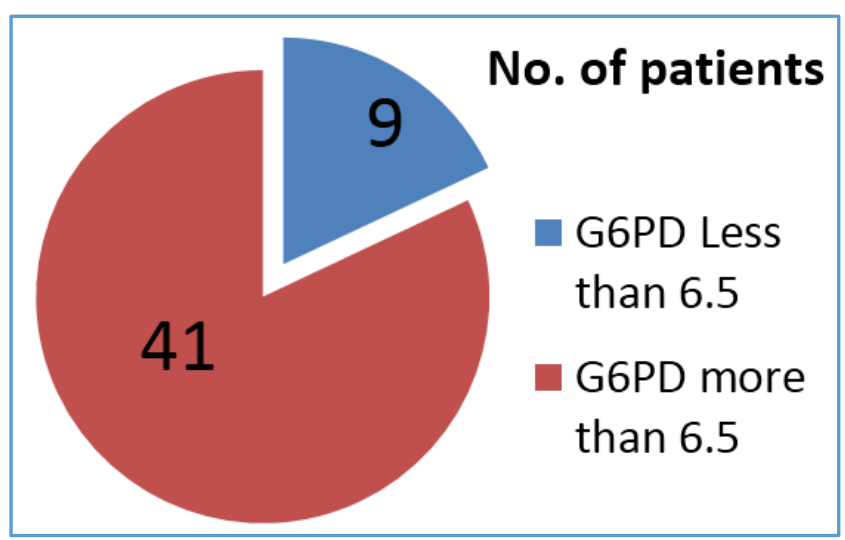

Graph 1. Shows number G6PD deficiency in patients

$18 \%$ of patients presented with G6PD value less than $6.5 \mathrm{u} / \mathrm{g} \mathrm{Hb}$ and $82 \%$ of patients presented with G6PD levels more than $6.5 \mathrm{u} / \mathrm{g} \mathrm{Hb}$.

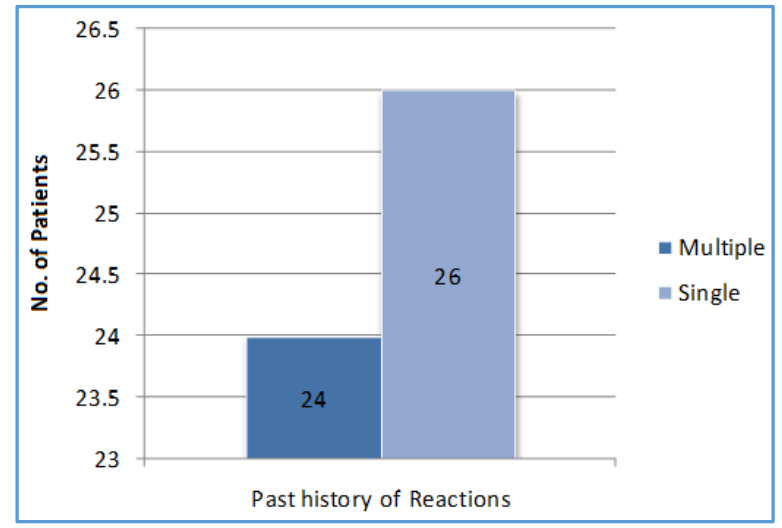

Graph 2. Shows number of patients having past history of reactions before starting on CDC therapy

$48 \%$ presented with single episode of reaction while $52 \%$ patients presented with multiple episodes of reaction and later all the patients were started on with CDC therapy.

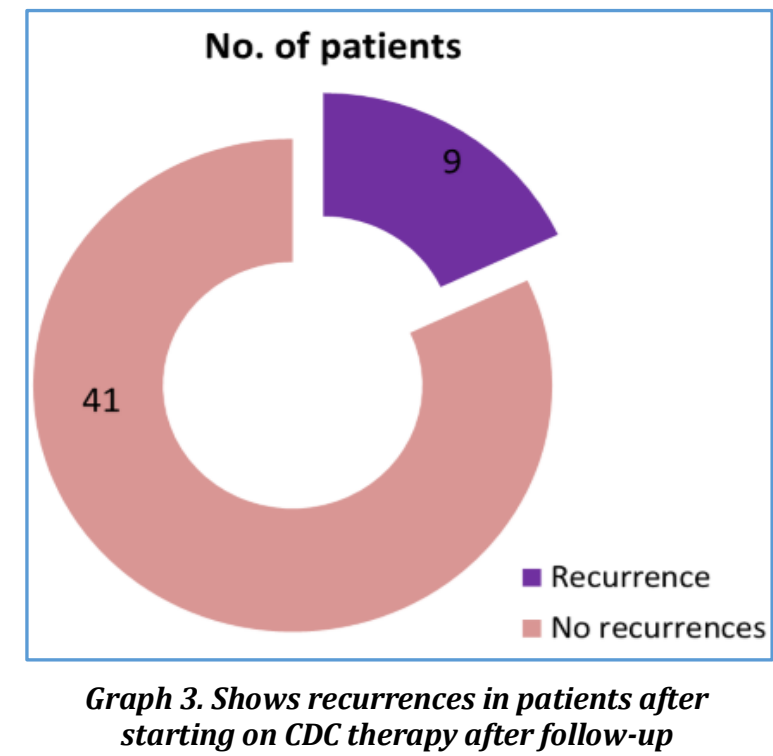

$18 \%$ of patients presented with recurrences and $82 \%$ of patients presented with no recurrences after starting on CDC therapy. Patients who had G6PD deficiency and were not started on Dapsone therapy, showed recurrences else all the patients were normal.

WHO has already researched from the year 2003 to 2016 stating the antimicrobial resistance in leprosy patients specifically Rifampicin showing the highest resistance among all other drugs.[8]

Hence, once monthly dose of Rifampicin is leading to further downgrading of the reaction and even causing resistance in patients taking anti-tubercular therapy. In our study we observed $10 \%$ of the patients having tuberculosis along with Hansen's disease, in such cases Indian type of MDT therapy was further causing resistant Tuberculosis, due once monthly dosage of Rifampicin due to which patients were started on with CDC therapy and $100 \%$ cure rate was achieved with no relapse.

Slit skin smear was positive for $74 \%$ of patients, while 26 $\%$ presented with negative bacterial index which included maximum of patients with type 1 reaction having tuberculoid pole of leprosy. 
Histopathology showed features of reversal reaction in $30 \%$ patients, Erythema Nodosum Leprosum features in $64 \%$ patients and 6\% showed both Erythema Nodosum Leprosum and Erythema Nodosum Nercroticans features.

\section{DISCUSSION}

Head to toe analysis of patients.

\section{Eye Changes Observed in Patients}

Since leprae bacilli have an affinity towards low temperature sites it enters the ocular tissues through hematological spread into the eyelids, adnexa and anterior parts of the eyeball. Eyebrows superciliary madarosis, loss of Strength of orbicularis, lagophthalmos was observed in patients. Presence of nodular lesions over eyebrows and eyelids, conjunctival redness due to exposure and episcleritis were also observed in few patients. Hence it becomes mandatory to have an ophthalmology checkup for all the leprosy patients.

\section{Nasal Cavity}

Patients presented with few basic presenting complains in which $68 \%$ patients had epistaxis due to depression of nasal bridge, septal perforation or destruction of Kiesselbach's plexus specially all patients with type 2 reaction complained of nasal bleed minimum of 2-3 episodes.

Nail changes like hypertrophy or complete destruction of nails were observed.

\section{Oral Cavity}

Upper incisors were seen lost in many lepromatous leprosy cases. Cobble stone appearance of the tongue with macroglossia was observed in few cases.

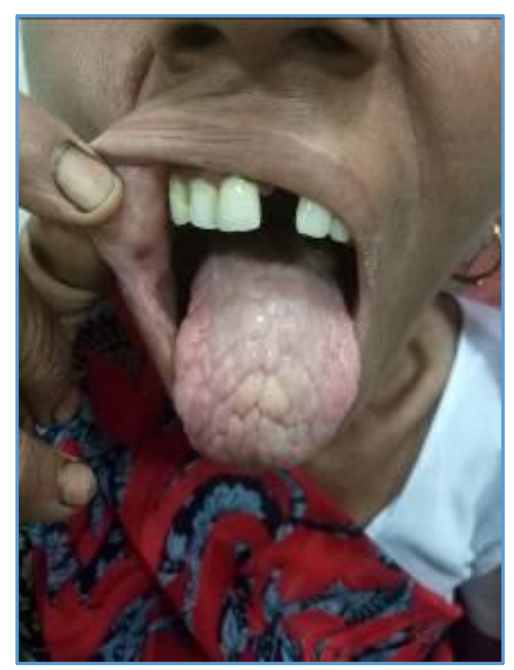

Figure 1. Cobble stone appearance with macroglossia and loss of upper incisor in Type 2 reaction

Horsiness of the voice was noticed in few patients due to laryngeal involvement seen in leprosy.

\section{Respiratory System}

Leprosy confines itself to upper respiratory tract only and lower respiratory tract and lungs are mostly spared but in the study, we came across $12 \%$ of the patients who gave history of reactivation of latent tuberculosis which was further confirmed with investigations and treatment was started accordingly.

\section{Gastrointestinal System}

No specific gastrointestinal involvement was observed in the patients. Except for the liver enzymes 34\% patients presented with abnormal SGOT levels while $18 \%$ presented with abnormal SGPT levels, few patients presented with deranged bilirubin levels and at very high levels MDT was stopped in those individuals.

\section{Myoskeletal System}

Joint pain was one of the major complains amongst $80 \%$ of patients since $66 \%$ of the patients are male and one of the cause can be leprous testicular atrophy which leads to decrease level of testosterone in an individual and can be a causative factor for osteoporosis and even gynecomastia was observed in few patients.

\section{Renal System}

Renal involvement in leprosy is the most common finding, the functional abnormalities such proteinuria which was found in $18 \%$ of the patients while $8 \%$ with calcium oxalate crystals and $20 \%$ patients presented with serum creatinine levels more than $1 \mathrm{~g} / \mathrm{dl}$.

\section{Lymphatic}

Lymph node involvement was observed in $16 \%$ of the patients in case of tuberculoid leprosy only the regional lymph node involvement was seen while in the case of lepromatous leprosy patients generalized lymphadenopathy was observed.

Vasculitis was observed in patients showing levido reticularis pattern and even in patients with long corticosteroid therapy. One patient also presented with varicose veins associated with type 2 reaction. Most of the patients presented with ichthyosis of the upper limbs and lower limbs.

\section{Haematological and Serological Study}

$22 \%$ patients presented with $\mathrm{Hb}$ level less than 9. 36\% patients presented with Total leukocyte cells value more than 11,500 and value of erythrocyte sedimentation rate more than 20 in $68 \%$ patients.

In G6PD deficient cases (below $6.5 \mathrm{u} / \mathrm{g} \mathrm{Hb}$ ), Dapsone induces hemolysis and compensatory reticulocytosis occurs leading on to high G6PD level. The peripheral blood smear Heinz bodies and Bite cells can be observed. We observed increased leucocyte counts and decreased red blood cell counts in almost every third case including G6PD deficient individuals. G6PD analysis before starting the MDT therapy is still not under general practice and hence so many patients die due to hemolytic anemia and cause remains unknown. In our study we made it mandatory for all the individuals to undergo G6PD analysis before starting on MDT therapy.

In the study, the recurrences were majorly observed in type 2 reaction patients rather than type 1 reaction, patients with G6PD deficiency who were not started on with the Dapsone therapy showed maximum number of recurrences even after starting on rest of the standard WHO therapy. Patients when started on with the therapy were advised to take at least 16 glasses of water per day as they came up with high rise in temperature due to reduced rate of rifampicin clearance from the kidneys and its increased toxicity. Patients were also advised complete sun protection as Clofazimine 
induces hyperpigmentation but in spite of several reminders patients presented with complete Clofazimine induced hyper pigmented face and over all hyper pigmentation of the body.

Almost all forms of lesion were observed in the patients as we have included all the poles of leprosy but maximum patients $90 \%$ presented with anesthetic patches, while $92 \%$ presented with hypo pigmented patches. Majority of type 2 reaction presented with tender nodular lesions $72 \%$ of the patients, rest are described with figures in the results.

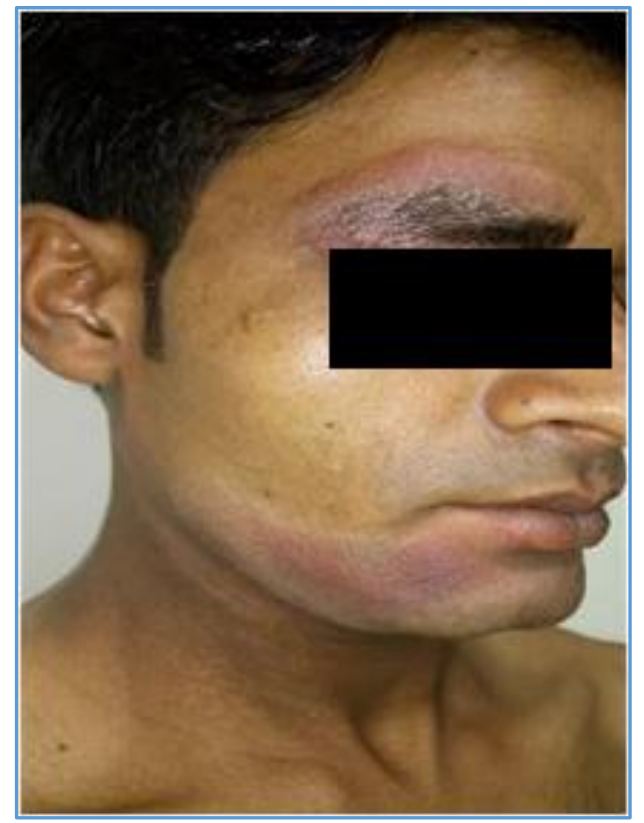

Figure 2. Edematous, erythematous plaques in type 1 reaction

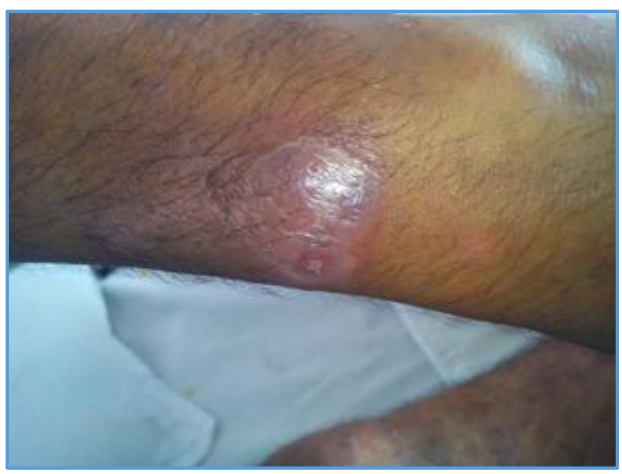

Figure 3. Erythematous, evanescent lesions Type 2 reaction

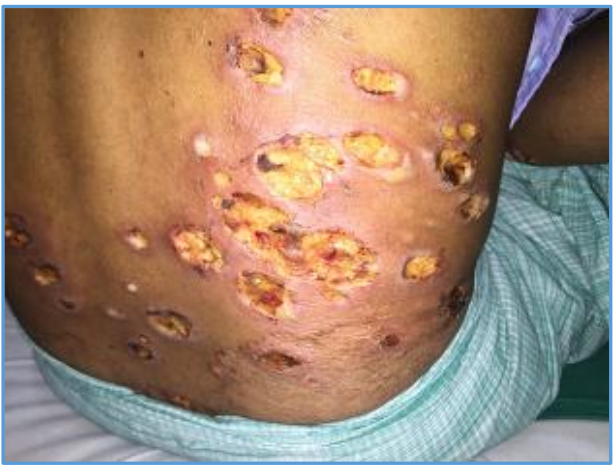

Figure 4. Erythema Nodosum Necroticans in case of Type 2 reaction
Trophic ulcers were observed in $12 \%$ of the patients and were prescribed with specific foot wears. All the patients were sent to physiotherapy department for specific exercises and footwear recommendation.

\section{Histopathology}

In the patients of type I reaction edema of the dermis with lymphocytic infiltration and epithelioid cells was observed commonly. In some specimens, giant cells and macrophages were also observed.

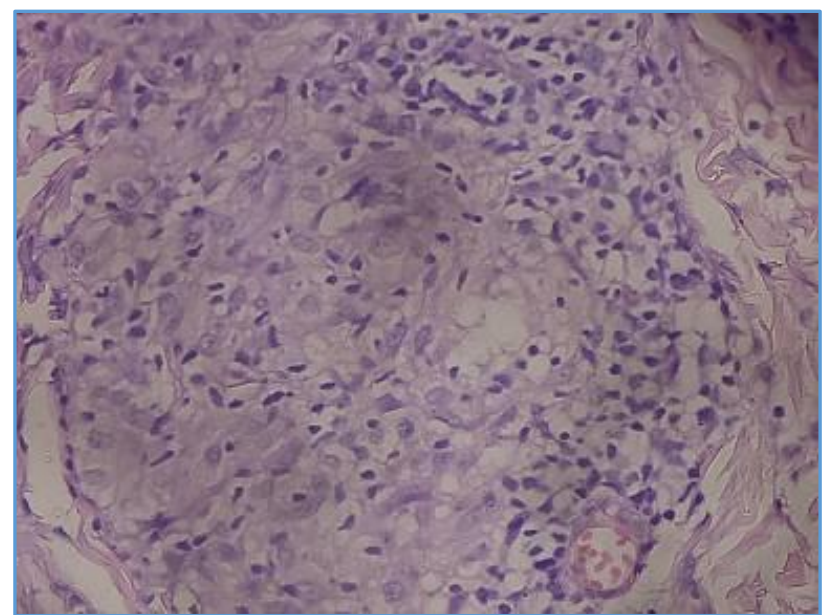

Figure 5. Type I reaction: Macrophages, lymphocytes, epithelioid cells and giant cells forming a granuloma in the dermis

In the specimens taken type 2 reaction patients vasculitis was observed in all the patients, increased vascularity due to PMNL infiltration and edema is observed. Lymphocytic predominance in type I upgrading reactions and type II reaction showed neutrophilic predominance, vasculitis and eosinophils occasionally.

Intense edema observed in the acute phase with rise in lymphocytes, occasional neutrophils and giant cells. Neutrophilic infiltration with vasculitis is the predominant features seen in type 2 reaction.

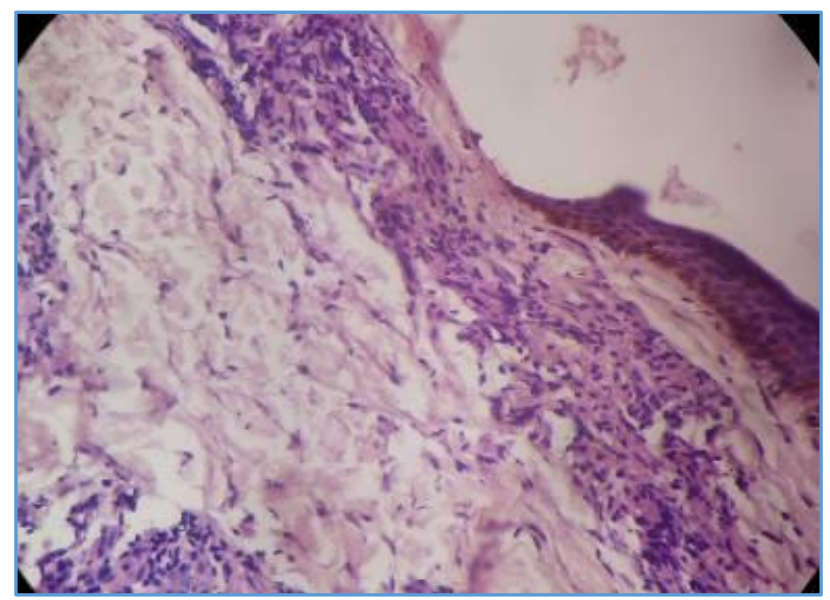

\section{Figure 6. Type II reaction: Foamy macrophages with polymorph neutrophils in the dermis}

Hence, histopathology serves as an important tool in confirming the diagnosis, type of reaction with the pole of reaction. It is also helpful in determining the down grading or upgrading of the reaction. 


\section{CONCLUSION}

During this whole study, we concluded that G6PD is one of the basic investigations to be analyzed before starting Dapsone therapy. CDC therapy given to the patients produces least amount of recurrences in case of reactions, hence it should be recommended for all the patients to avoid any recurrences and resistance. Rifampicin resistance causes downgrading of reaction due to once monthly dosage in MDT therapy and further resistance in the patients taking ATT as well. Clinical analysis of all the signs and symptoms are a must when it comes to reactions. Histopathology plays a very important role in confirming the diagnosis and slit skin smear test is a mandatory for all the Hansen's patients.

Leprosy is still considered a taboo in our society it is high time we accomplish this dream of "India free from leprosy". This is just our contribution towards it.

\section{REFERENCES}

[1] Programme Implementation Plan (PIP) for 12th plan period (2012-2013 to 2016-2017). Central Leprosy Division, Directorate General of Health Services, Ministry of Health and Family Welfare, Govt. of India, Accessed on December 16, 2014: p. 38. http://nlep.nic. in/pdf/Final\%20PIP,on\%203\%20May\%202013.pdf
[2] Breathnach AS. Electron microscopy of cutaneous nerves and receptors. Journal of Investigative Dermatology 1977;69(1):8-26.

[3] McDermott-Lancaster RD, McDougall AC. Mode of transmission and histology of $\mathrm{M}$. leprae infection in nude mice. International Journal of Experimental Pathology 1990;71(5):689-700.

[4] Girdhar BK. Skin to skin transmission of leprosy. Indian Journal of Dermatology, Venereology and Leprology 2005;71(4):223-5.

[5] Mazini PS, Alves HV, Reis PG, et al. Gene association with leprosy: a review of published data. Frontiers in Immunology 2016;6:658.

[6] Putinatti MS, Lastória JC, Padovani CR. Prevention of repeated episodes of type 2 reaction of leprosy with the use of thalidomide $100 \mathrm{mg} /$ day. Anais Brasileiros De Dermatologia 2014;89(2):266-72.

[7] Rao PS, Sugamaran DS, Richard J, et al. Multi-centre, double blind, randomized trial of three steroid regimens in the treatment of type- 1 reactions in leprosy. Leprosy Review 2006;77(1):25-33.

[8] World Health Organisation. Antimicrobial resistance in leprosy. Report of a global consultation. 27-28 October 2016, Kathmandu, Nepal. SEA-GLP-2016.5 pg6-30. 